\title{
Appraisal of Optimum Economic Life for Farm Tractor: A Case Study
}

\author{
V. Pagare ${ }^{1}$, S. Nandi ${ }^{1 *}$ and D.K. Khare ${ }^{2}$ \\ ${ }^{1}$ Central Institute of Agricultural Engineering, Bhopal-462038, M.P., India \\ ${ }^{2}$ College of Agricultural Engineering, JNKVV, Jabalpur-482004, M.P., India \\ "Corresponding author: subhasisnandi2@gmail.com
}

\begin{abstract}
Agricultural equipment gets deteriorated mechanically and their functionality decreased with time and usage. In order to manage such equipment, it requires higher operating and maintenance cost, as a result of this, there is a need to replace them. Decision making about the replacement of used farm equipment with a new similar one is one of the important aspects of farm machinery management. Based on that criterion, the objective of the investigation was decided to estimate the economic operational life of tractors in the central region of Madhya Pradesh, India and to evaluate the effect of different parameters on economic life, which would add value to the profitable management decision. The tractor data collected were from government agricultural centres in the different regions of M.P. and categorized them into different groups based on their horsepower rating. Considering the preventive replacement policy the total annual average costs of tractors were estimated taking account into the repair cost and depreciation cost. The time period (in year), when the total annual average cost touched its minimum value, was decided as the economic life of a tractor. There is a negative correlation $(r=-0.835)$ found between size (HP) of tractors and their economic life. And an empirical relation based on multiple regression analysis has been generated to predict the economic operational life of a tractor using per unit repair cost and annual usage (hours) as variables.
\end{abstract}

Keywords: Optimum life, annual average cost, repair cost, depreciation, replacement

The introduction of modern technology in agriculture resulted in changing the growth trend of farm production. Tractors and farm machinery are important samples of this modern technology. The use of machinery constitutes one of the important capital inputs in agricultural production. Tractor is the most important power farming machine and its effects on agriculture is huge. It requires a high initial capital investment and its costs have great influence on farm business profit. Knowledge of tractor economics has a prime importance in making decision related to the replacement policy and correct preparation of farms budget (Morris, 1988).

Management of farm machinery is one of the important aspects of determination of replacement time of farm machinery in relation to their economical and technological conditions. Proper agricultural machinery management therefore requires keeping them in good working condition, having them repaired or reconditioned as at when due, selection of suitable types and sizes, keeping cost record and controlling it (Dauda and Ashami, 2000). In most mechanized farms, economic management of power and machinery is often overlooked as a factor in farm profits, yet it is usually a most significant factor (Hunt, 1974, 1977; Igbeka, 1986). It was reported that farmers could reduce their repair and maintenance costs by $25 \%$ by improving routine maintenance procedure (Bukhara et al. 1988). (Ward, 1990) presented a cost model for tractor ownership as a function of annual use hours. It can be inferred from his finding that reduction in repair costs by careful operation and adequate maintenance could result in a significant reduction in tractor ownership costs. The ownership 
cost and operational cost accounts for 35-50\% Of agricultural production (Anderson 1988) and these costs have direct bearing on the economic life or optimum life of machinery. Economic or optimum life for a machine presents a time period based on constant and variable costs that using the machine is economical (ASAE Standards EP496, 2006; Hunt 2001). Each machine has a determined economical life that thereafter using the machine is not economical.

The replacement criteria, where the optimal length of the operational life of tractor or its components is determined, is performed based on the economic factors rather than purely on physical factors, where the tractor is kept until it is either worn out or unable to perform its function satisfactorily before a change is considered. In general, there are two fundamental replacement strategies: replacement on failure and preventive replacement (Eilon et al. 1966). The vehicle replacement problem belongs to a group of preventive replacement strategies where an optimal utilization period is determined as an age of a vehicle to replacement assuring minimization of the expected vehicle operational costs per unit time. The optimization of the utilization period of a tractor can be based on minimization of the expected operational costs per time unit, maximization of an operational profit per unit time (Christer and Goodbody, 1980; Dohi et al. 2006). There are different studies being carried out from different prospective to finding out the suitable replacement or optimum life of tractors. Ajibade et al. (2014), Amiens et al. (2015) and Ekeocha et al. (2011) investigated equipment replacement from the cost minimization point of view, Jin and Kite-Powell (2000) and Offiong et al. (2013) examined vehicle replacement time from the profit maximization perspective. Nevertheless, the two scenarios are analogous to two sides of a coin because while the cost minimization perspective of equipment replacement explains how optimum replacement time is critical to cost minimization of a firm, the profit maximization model shows how cost minimization enhances profit maximization. Thus, the two perspectives are complementary. Belchet (2008) examined the equipment replacement problem from the repair cost limit point of view. From this perspective, a system is replaced as soon as the repair cost hits a given level. Based on ASAE, replacement age for a machine that is placed on economic life arrives typically before fundamental breakdowns resulted worn out and technological disabling (ASAE Standards S495, 2006).

From the reviews, it is clear that there are many factors contributing to the optimum life of tractor but, among them the minimization of operating cost per hour plays a key to the optimum use of tractor of any size. And that will ultimately lead to the maximization of profit of owner. In our study we are trying to find out the optimum or economical operational life of tractors of the central region of Madhya Pradesh, India and establish a relationship to predict the economical life based on the operating cost per hour and annual use hour of tractors. Determining economical life for farm tractor provides farmers an opportunity to evaluate the performance of machinery economic.

\section{MATERIALS AND METHODS}

The study was carried out in the central region of Madhya Pradesh, India. Data in this study were collected randomly from the concerned government offices of the region, which keep records of the machinery used by the farmers of the reason, of different tractors under use. The information gathered were tractor characteristics (mainly the size of tractor) and economics such as annual use of tractor, lubrication cost, repair \& maintenance cost, labor cost and fuel use cost etc. The randomly selected tractors were categorized in six different groups according to their horsepower rating and kept our all information for 10 years from the starting of purchase of tractor, as mentioned in the Table 1 below. The mean value of all estimations from each group was considered in this paper.

Table 1: Categorizing tractors into different groups

\begin{tabular}{cccc}
\hline Groups & $\begin{array}{c}\text { HP of } \\
\text { tractor }\end{array}$ & $\begin{array}{c}\text { No. of } \\
\text { tractors }\end{array}$ & $\begin{array}{c}\text { Time period of Data } \\
\text { taken (years) }\end{array}$ \\
\hline I & 60 & 3 & $2001-2011$ \\
II & 55 & 3 & $2001-2011$ \\
III & 50 & 4 & $2003-2013$ \\
IV & 45 & 1 & $2003-2013$ \\
V & 40 & 3 & $2003-2013$ \\
VI & 35 & 2 & $1998-2008$ \\
\hline
\end{tabular}

\section{Machinery Cost}

Machinery costs are mainly divided into two 
categories, fixed cost and running cost. The running costs always increase proportionally with the amount of operational use over time, while fixed costs are independent of use. The cost of interest on the machinery investment, taxes, housing and insurance are dependent on time, similarly the costs of fuel, lubrication, daily services and labor wages are associated with use of machinery. Only two cost items, depreciation cost and repair and maintenance cost seem to be function of time and use. In this study, instead of considering all the costs, it is emphasized on these two costs.

\section{Depreciation}

Depreciation is a cost resulting from wear, obsolescence, and age of a machine. The degree of mechanical wear, introduction of new technology or a major design change may make an older machine suddenly obsolete, causing a sharp decline in its salvage value. But age and accumulated hours of use usually are the most important factors in determining the remaining value $(\mathrm{V})$ of a machine at any time. There are different techniques are available to estimate the depreciation of a machinery, but in this study double- declining balance method is used in calculating the depreciation of tractors under study. It reflects the actual value of a machine at any age rather than the value found from other methods. With the declining balance method, a machine depreciates a different amount for each year, but annual percentage of depreciation is constant. It can be calculated by following expression;

$$
\begin{aligned}
& D=V_{n}-V_{n+1} \\
& V_{n}=P(1-X / L)^{n} \\
& V_{n+1}=P(1-X / L)^{n+1}
\end{aligned}
$$

Where, $D$ (Depreciation), is amount of depreciation charged for year $n+1, n$, is a number representing age of the machine in years at beginning of year in question, $V$, is remaining value/salvage value at any time and $x$, is ratio of depreciation rate used to that of straight-line method ( $x$ may be any value between 1 and 2). If $x=2$, the method is called a double-declining-balance method.

\section{Repair and Maintenance ( $R$ \& $M)$}

The anticipated annual cost of repair for any machine is highly uncertain. It is the combine expenditure for parts and labour. In two different cases this cost is considered, while reconditioning the wear out parts and complete replacement of failed parts. In this case the yearly $R$ \& $M$ costs are collected from the sources for each tractor and accumulated for 10 years.

\section{Optimum life}

The primary decision is usually whether or not an existing machine should be kept for at least one more year, or replaced with a different machine. To make this decision it is first necessary to determine the optimal replacement time, in a cost minimizing sense. The optimization criterion considered here is the (expected) long run cost per unit of time, which is more general in nature. The cost associated in the replacement process is termed as a holding cost or total cost of machine, which is the combination of accumulated repair and maintenance (variable cost) and depreciation (fixed) cost. The total costs associated with this optimal replacement cycle are then converted to an equivalent stream of equal annual costs at the appropriate rate of time preference (i.e., equivalent annuities). If the present cost of maintenance of the existing machine is equal or closer to the equivalent annuity cost (avg. annual cost) or when the annuity cost of the machine is in its minimum value then the existing machine should be replaced with a new one to gain maximum profit. We can write the optimization criterion in the following form,

$$
B^{T}=M^{T} / S^{T}
$$

Where, $B^{T}$ represents the optimum cost, $M^{T}$ represents the expected total cost associated with a replacement cycle and $S^{T}$ represents the expected length in year of a replacement cycle. $T$ denotes the time (T. Aven, 1992).

\section{Statistical Analysis}

"SPSS 23" version of statistical analysis software was used to analyze ANOVA, Correlation and Multiple linear regressions of collected data at $95 \%$ level of confidence in all methods. 


\section{RESULTS AND DISCUSSION}

\section{Depreciation analysis}

Depreciation, often the largest cost of farm machinery, measures the amount by which the values of a machine decrease with the passage of time whether used or not. The Fig. 1 represents the relationship between the value of tractor and hours of use. It is seen that the depreciation tends to be greater at first, especially for a machine purchased new, but declines over time.

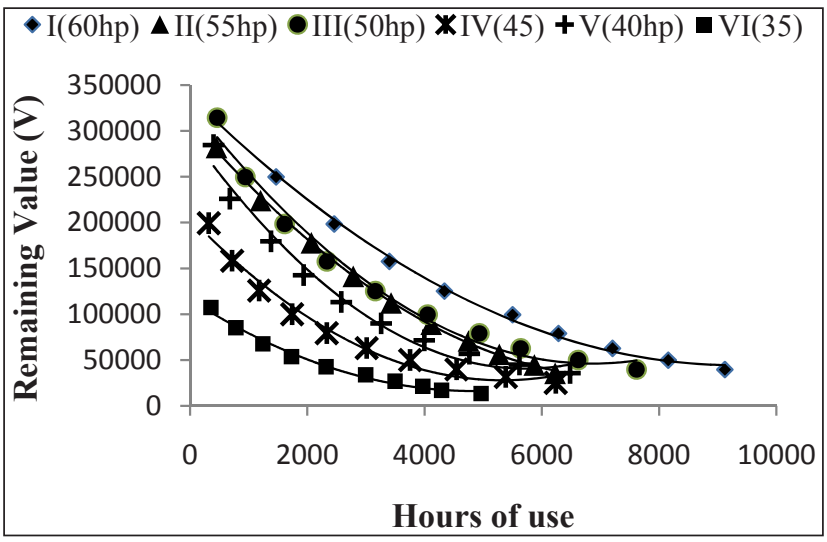

Fig. 1: Remaining value (V) of tractors vs cumulative hours of use

The decline in depreciation owed to the sharp reduction in the trade-in value or scrap value of tractor over the years. To find the co-relation between the depreciation of tractors and their increasing hour of use, different regression equations are tried and the best fit equations, which are non-linear in nature found in the process, are mentioned in the Table 2 for different size of tractors. Since horsepower, initial cost and annual hour of uses are the variables that mostly influence the value of Tractor, the ANOVA test was used to identify any differences in depreciation behaviour between tractors of different horsepower categories i.e. (less than $50 \mathrm{hp}$ and greater than $50 \mathrm{hp}$ ). From the analysis it was found that $\mathrm{P}=0.002$, which is significant in nature. It shows that higher horsepower tractors are depreciated rapidly than the lower horsepower tractors. Though, depreciation rate $(20 \%)$ is constant for every year, it could be due to the high initial cost and intense annual hour of usage of larger size tractors compare to smaller size tractors. Similar studies have been done to establish relationship between horsepower of tractors and their trade-in values using cluster analysis by (Perry et al. 1990).

\section{Optimum replacement time estimation}

Table 2 presented the annual maintenance cost and average annual cost of different sizes of tractors with respect to the years of operation. It shows an increasing trend of $\mathrm{R} \& \mathrm{M}$ (repair and maintenance) cost over the year, as parts wear out and maintenance requirement rises. The average annual costs at the initial years were high and that dropped to their lowest value at certain year and then begins to rise, due to the increasing maintenance cost with age. The lowest values of the average annual cost, which is considered to be the appropriate time for replacement are found to be $5^{\text {th }}$ year $(4339.71 \mathrm{~h}), 5^{\text {th }}$ year $(3430.46 \mathrm{~h}), 6^{\text {th }}$ year $(4052.78 \mathrm{~h}), 6^{\text {th }}$ year $(3012 \mathrm{~h})$, $6^{\text {th }}$ year $(3262 \mathrm{~h})$ and $9^{\text {th }}$ year $(4290.92 \mathrm{~h})$ for I, II, III, IV, V and VI groups of tractors respectively. Fig. 2-7 shows the interaction between the maintenance costs and average annual cost with ages (years). The point of intersection is read as the optimum replacement point where present cost of maintenance equal to the annuity cost of owning a tractor. After the optimum replacement period owning a tractor would not be profitable for the owner. In order to see the correlation between the horsepower and the optimum life a tractor Pearson's correlation analysis is used. And a negative value is found i.e., Pearson coefficient $(r)=-0.835$, which indicates that increase

Table 2: Regression Model summery

\begin{tabular}{cccccc}
\hline Groups & Regression Equation & Intercept $(\mathrm{c})$ & Coefficient (a) & Coefficient (b) & $\mathbf{R}^{2}$ \\
\hline I & $\mathrm{y}=\mathrm{ax}^{2}-\mathrm{bx}+\mathrm{c}$ & 337763 & 0.0034 & 63.041 & 0.9975 \\
II & $\mathrm{y}=\mathrm{ax}^{2}-\mathrm{bx}+\mathrm{c}$ & 354117 & 0.0024 & 55.509 & 0.9994 \\
III & $\mathrm{y}=\mathrm{ax}^{2}-\mathrm{bx}+\mathrm{c}$ & 333075 & 0.0037 & 65.301 & 0.9986 \\
IV & $\mathrm{y}=\mathrm{ax}^{2}-\mathrm{bx}+\mathrm{c}$ & 232129 & 0.0013 & 33.447 & 0.9976 \\
V & $\mathrm{y}=\mathrm{ax}^{2}-\mathrm{bx}+\mathrm{c}$ & 215516 & 0.0037 & 52.985 & 0.9984 \\
VI & $\mathrm{y}=\mathrm{ax}^{2}-\mathrm{bx}+\mathrm{c}$ & 118600 & 0.001 & 23.189 & 0.9974 \\
\hline
\end{tabular}


in horsepower leads to reduce in the optimum life of a tractor.

Table 3: observed parameters of different groups

\begin{tabular}{ccccc}
\hline Groups & $\begin{array}{c}\text { Replacement } \\
\text { age (year) }\end{array}$ & $\begin{array}{c}\text { Annual } \\
\text { usage( } \mathbf{h})\end{array}$ & $\begin{array}{c}\text { Power } \\
\text { (HP) }\end{array}$ & $\begin{array}{c}\text { R\&M cost } \\
(₹ / h)\end{array}$ \\
\hline I & 5 & 965 & 60 & 161.02 \\
II & 5 & 930 & 55 & 158.71 \\
III & 6 & 761 & 50 & 194.00 \\
IV & 6 & 531 & 45 & 202.00 \\
V & 6 & 502 & 40 & 229.21 \\
VI & 9 & 480 & 35 & 135.60 \\
\hline
\end{tabular}

\section{Empirical model to predict replacement year}

Table 3 represents the Observed values of different variables such as replacement year, annual usage, size of tractor (in terms of HP) and repair and maintenance cost $(\mathrm{R} \& \mathrm{M})$ of different tractors.
Based on these data, a multiple regression analysis was carried out to predict the optimum life of a tractor and to check linearity in the relationship between variables. By the analysis, an empirical equation is generated considering only two independent variables i.e., annual usage and $\mathrm{R} \&$ $\mathrm{M}$ cost. Though, size of tractor was considered as one of its independent variables but it did not find significance in the model. The empirical equation states as;

$$
Y=C-a X_{1}-b X_{2}
$$

Where, Y: Replacement year (dependent variable)

$C$ : constant, $X_{1}$ : annual usage, $X_{2}: R \& M$ cost per hour and $a, b$ : coefficients

By regression analysis of the observed data, the proposed equation (Eqn. 5) was found to be the best

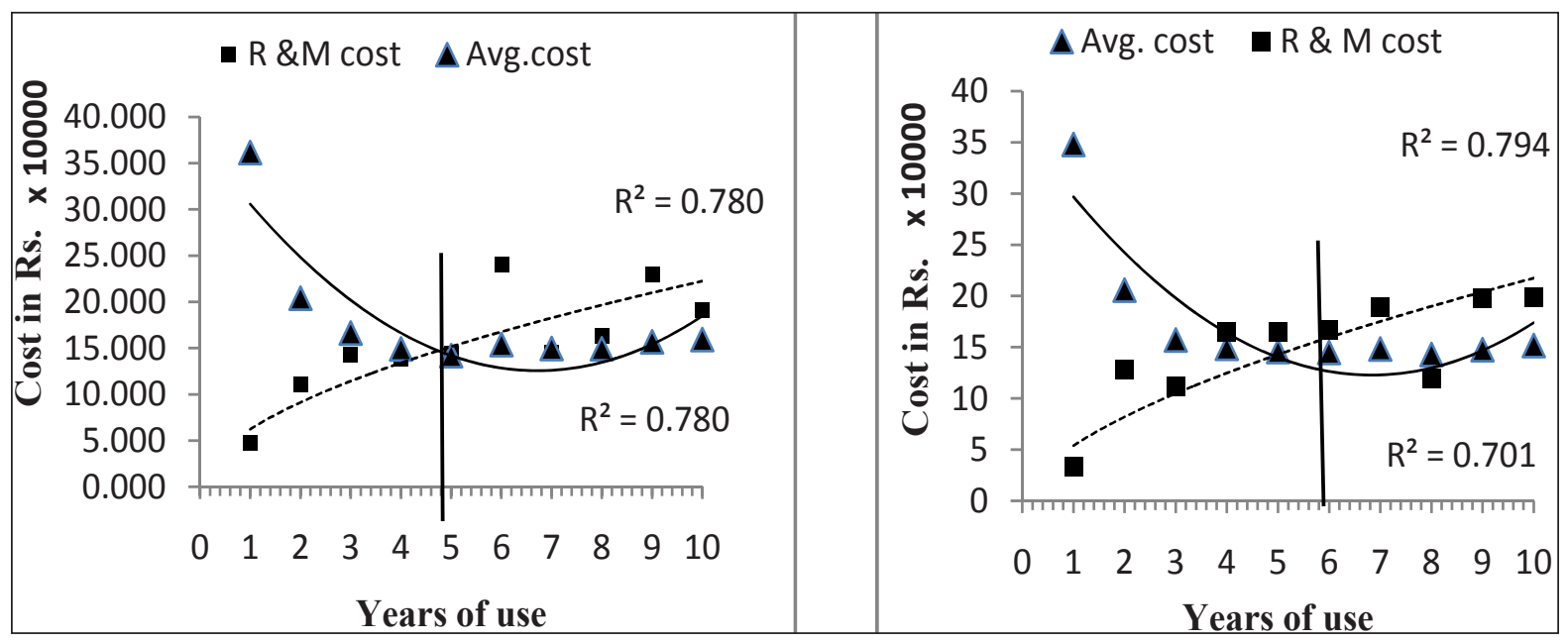

Fig. 2 (I - 60hp)

Fig. 3 (II- 55hp)

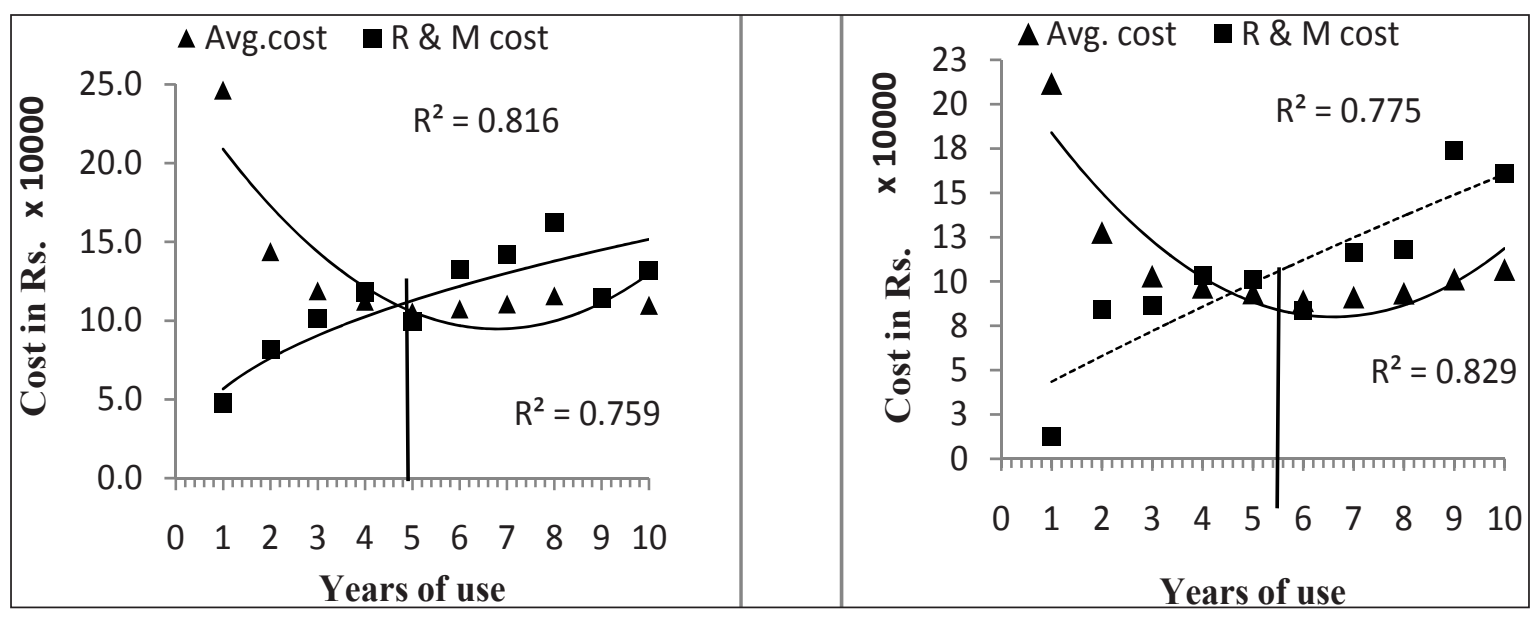

Fig. 4 (III- 50hp)

Fig. 5 (IV- 45hp) 


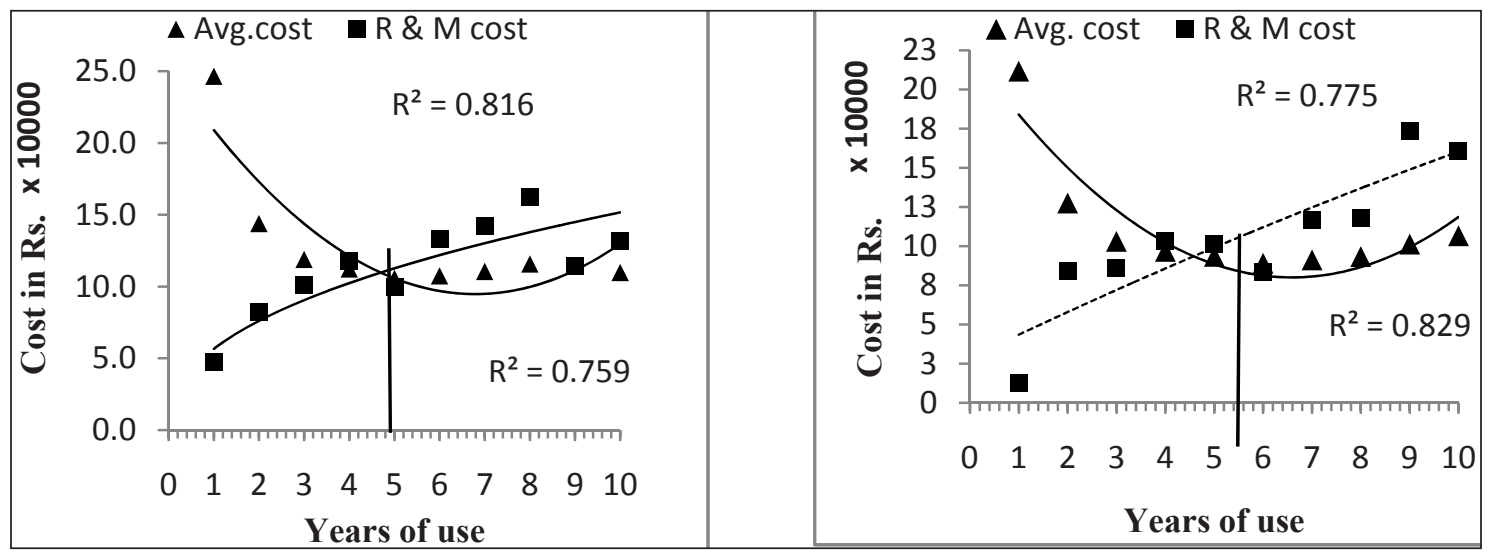

Fig. $6(\mathrm{~V}-40 \mathrm{hp})$

Fig. 7 (VI- 35hp)

Fig. 2-7: Relation between R \&M cost and annual average cost with respect to years of use for different groups of tractor

fit with coefficient of determination $\mathrm{R}^{2}$ and adjusted $\mathrm{R}^{2}$ (from the table 5) are 0.919 and 0.865 respectively. The ANOVA results show that the $p=0.02$ for this model, which is significant and rejects the null hypothesis, so we can assume that there is a linear relation exist between variables. In the Table 4 coefficients of estimate are mentioned and their significance level indicates the impact of variables on the prediction value. The negative coefficients of both the independent variables show that every increase in the annual usage and $R$ \& $M$ cost of a tractor will lead to decrease in optimum life. Fig. 8-9 show that, in the model, the requirements of linearity, normality and homoscedasticity are adhered, since no clear tendency is seen in the dispersion between the predicted and observed values of the residuals.

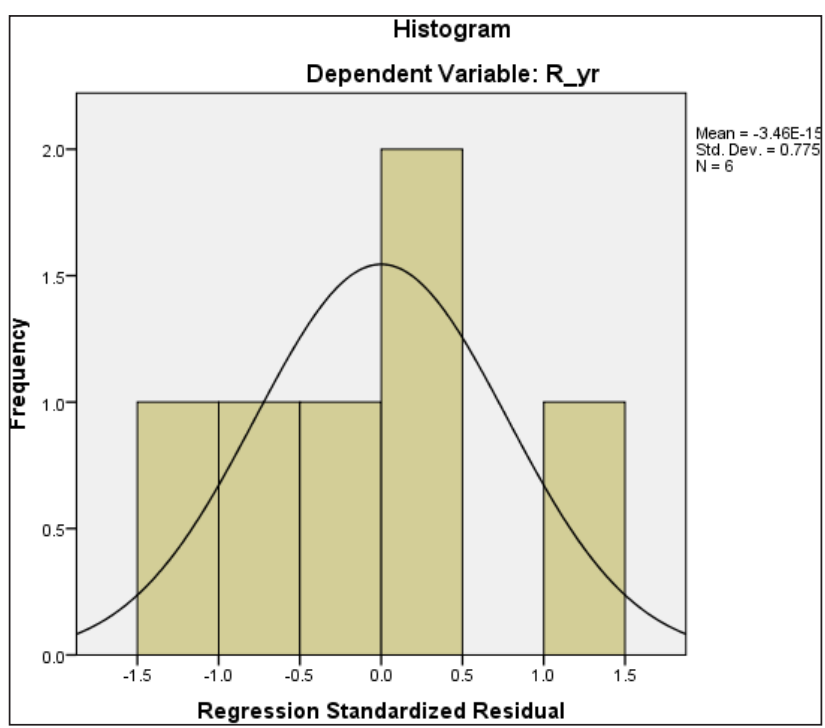

Fig. 8 Histogram of standardized residual

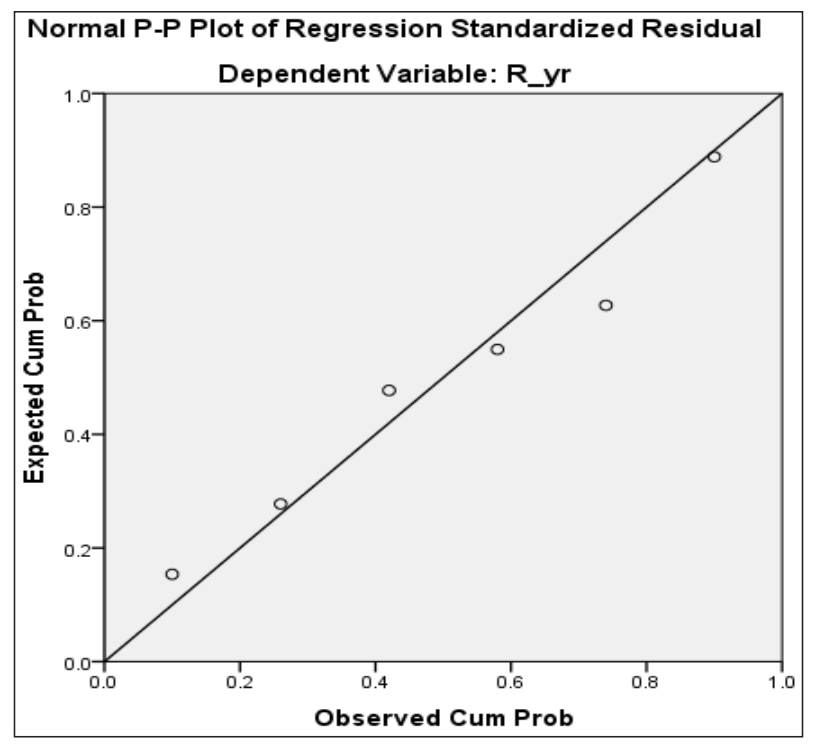

Fig. 9: Normal probability plot of regression standardize residual

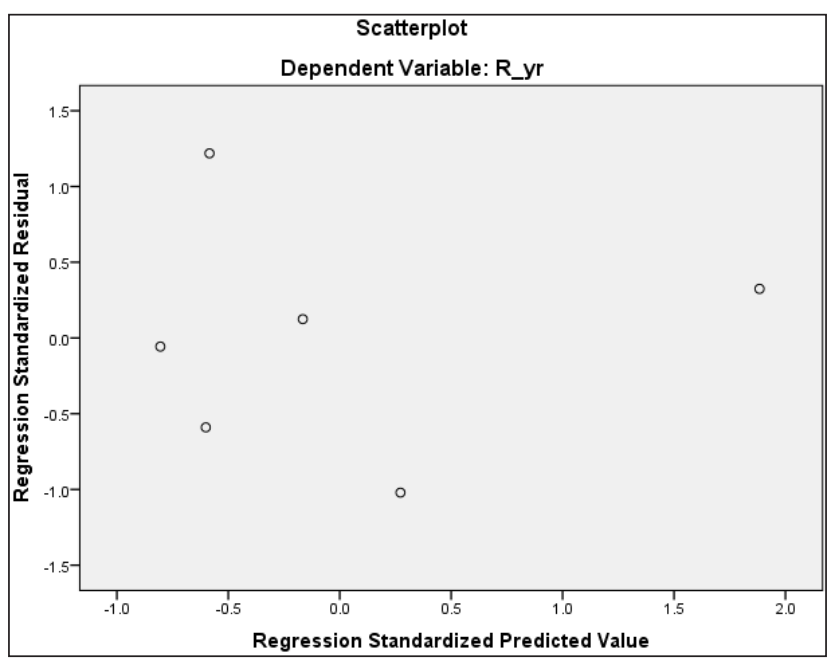

Fig. 10: Dispersion plot of regression standardize residual 
Table 4: Annual R \&M cost and estimated average annual cost for different groups of tractor

\begin{tabular}{cccccccccccccc}
\hline & \multicolumn{2}{c}{ I(60hp) } & \multicolumn{2}{c}{ II(55h) } & \multicolumn{2}{c}{ III(50hp) } & \multicolumn{2}{c}{ IV(45hp) } & \multicolumn{2}{c}{ V(40hp) } & \multicolumn{2}{c}{ VI(35) } \\
\cline { 2 - 13 } Years & $\begin{array}{c}\text { R \& M } \\
\text { cost }\end{array}$ & $\begin{array}{c}\text { Avg. } \\
\text { Annual } \\
\text { cost }\end{array}$ & $\begin{array}{c}\text { R \& M } \\
\text { cost }\end{array}$ & $\begin{array}{c}\text { Avg. } \\
\text { Annual } \\
\text { cost }\end{array}$ & $\begin{array}{c}\text { R \& M } \\
\text { cost }\end{array}$ & $\begin{array}{c}\text { Avg. } \\
\text { Annual } \\
\text { cost }\end{array}$ & $\begin{array}{c}\text { R \& M } \\
\text { cost }\end{array}$ & $\begin{array}{c}\text { Avg. } \\
\text { Annual } \\
\text { cost }\end{array}$ & $\begin{array}{c}\text { R \& M } \\
\text { cost }\end{array}$ & $\begin{array}{c}\text { Avg. } \\
\text { Annual } \\
\text { cost }\end{array}$ & $\begin{array}{c}\text { R \& M } \\
\text { cost }\end{array}$ & $\begin{array}{c}\text { Avg. } \\
\text { Annual } \\
\text { cost }\end{array}$ \\
\hline 1 & 47196.3 & 361621.4 & 33542.2 & 347967.4 & 47759.5 & 246359.6 & 12455.7 & 211705 & 96880.9 & 381276 & 31816.0 & 139060 \\
2 & 110984.2 & 203979.9 & 127985.6 & 205653.6 & 82083.9 & 143805.7 & 84431.8 & 127585 & 103857.5 & 213331 & 61798.1 & 89404 \\
3 & 142892.1 & 166499.1 & 111465.6 & 157139.4 & 101392.3 & 118855.6 & 86500.0 & 103043 & 105696.9 & 161970 & 94516.0 & 85270 \\
4 & 138331.9 & 149258.3 & 150337.5 & 145239.9 & 118081.7 & 112220.1 & 103649.5 & 96731 & 125780.3 & 143697 & 75872.4 & 79442 \\
5 & $144406.8^{*}$ & $141806.3^{*}$ & 165180.5 & 142746.4 & $99478.8^{*}$ & $105577.9^{*}$ & 101129.6 & 93504 & 124053.6 & 133906 & 77280.7 & 74999 \\
6 & 240099.7 & 153897.7 & $167090.0^{*}$ & $142512.8^{*}$ & 132900.6 & 107421.4 & $83674.6^{*}$ & $89146^{*}$ & $156839.1^{*}$ & $133847^{*}$ & 64011.7 & 71704 \\
7 & 144860.4 & 149684.9 & 189229.7 & 146264.9 & 142109.8 & 110531.5 & 116607.0 & 91218 & 192260.3 & 139549 & 78636.8 & 68269 \\
8 & 163677.0 & 149403.0 & 119901.2 & 140938.5 & 162175.6 & 115704.2 & 118389.7 & 93327 & 193285.9 & 144429 & 72778.1 & 64390 \\
9 & 230334.2 & 156961.3 & 198062.4 & 145851.6 & 114625.6 & 114678.6 & 173731.2 & 101352 & 146037.5 & 143311 & $63083.4^{*}$ & $60423^{*}$ \\
10 & 191472.6 & 159387.1 & 198478.5 & 150089 & 71697.2 & 109732.8 & 160966.3 & 106664 & 124600.6 & 140513 & 94323.6 & 66463 \\
\hline
\end{tabular}

* indicates the appropriate replacement year, where average annual cost of tractor is closer to the repair and maintenance cost.

Table 5: Coefficients of dependent variable

\begin{tabular}{|c|c|c|c|c|c|c|}
\hline \multirow[t]{2}{*}{ Model } & \multicolumn{2}{|c|}{$\begin{array}{c}\text { Unstandardized } \\
\text { Coefficients }\end{array}$} & \multirow{2}{*}{$\begin{array}{c}\begin{array}{c}\text { Standardized } \\
\text { Coefficients }\end{array} \\
\text { Beta } \\
\end{array}$} & \multirow[t]{2}{*}{$t$} & \multirow[t]{2}{*}{ Sig. } & \multirow{2}{*}{$\begin{array}{l}\text { Collinearity } \\
\text { (VIF) }\end{array}$} \\
\hline & B & Std. Error & & & & \\
\hline (Constant) & 15.829 & 1.803 & & 8.779 & .003 & \\
\hline Annual usage (a) & -.006 & .001 & -.940 & -5.396 & .012 & 1.129 \\
\hline$R \& M \cos t / h(b)$ & -.029 & .007 & -.686 & -3.935 & .029 & 1.129 \\
\hline
\end{tabular}

Table 6: Model Summery

\begin{tabular}{cccc}
\hline $\mathbf{R}$ & R Square & Adjusted R Square & Std. Error of the Estimate \\
\hline .959 & .919 & .865 & .53997 \\
\hline
\end{tabular}

\section{CONCLUSION}

The objective of this study was to estimate the optimum life of a tractor and establish a relationship between the replacement life and other factors such as maintenance cost, annual usage of tractor and sizes, affecting the economic life of a tractor. Following outcomes are found:

- In an ideal condition the increase of total cost can give a general picture of when to replace a particular tractor but, it cannot give a precise answer. It is to note that the estimates for repair and maintenance cost project them increase gradually over time but, in reality it tends to be quite variable from time to time. So, being able to decide when the large cost needed is key consideration in deciding when to replace.
- It is also found that annual usage and repair maintenance cost per hour have significant impact on deciding the optimum life of a tractor. Based on that an empirical model is developed to accurately predict the optimum life of a tractor when annual usage and maintenance cost per hour are known.

- There is significant correlation between the horsepower and the optimum life of a tractor, as it shows ( $\mathrm{r}=-0.835)$, which could be owed to the variant workloads and hours of use of tractor in higher HP range.

\section{REFERENCES}

Ajibade, A.D., Odusina, M.T., Rafiu, A.A., Ayarinde, A.W., Adeleke, B.S. \& Babarinde, S.N. 2014. The use of replacement model to determine the appropriate time to 
replace a deteriorating industrial equipment. IOSR Journal of Mathematics, 10(2): 9-13.

Amiens, E.O., Oisamoje, M.D. \& Inegbenebor, A.U. 2015. A dynamic programming approach to replacement of transport vehicles in Benin City, Nigeria. British Journal of Mathematics \& Computer Science, 6(3): 204-214.

Anderson, A.W. 1988, Factors affecting machinery costs in grain production. ASAE paper No. 88-1057.

ASAE Standards EP496. Agricultural Machinery Management Engineering Practice. 2006.

ASAE Standards S495. Uniform Terminology for Agricultural Machinery Management. 2006.

Aven, T. 1992. Reliability and Risk Analysis. Elsevier Science Publishers Ltd..

Belchet, E.F. 2008. Afirst passage time problem in system replacement. Proceedings of the first international conference on applied operational research. Tabir Institute for Operational Research, System Design and Financial Services, 1: 222-229.

Bukhari, S.B., Baloch, J.M. \& Naqvi, S.H. 1988. "Cost of operating tractors on Quetta farm, Pakistan", AMA, 19(1): 14-19.

Christer, A. \& Goodbody, W. 1980. Equipment replacement in an unsteady economy. Journal of the Operational Research Society, 31(6): 497-506.

Dauda, A. \& Ashami, B. 2000. "Agricultural machinery utilization in Borno State", Nigerian Journal of Engineering Management, 1(4): 23-7.

Dohi, T., Ashioka, A., Kaio, N. \& Osaki, S. 2006. Statistical estimation algorithms for repairs-time limit replacement scheduling under earning criteria. Computers and Mathematics with Applications, 51: 345-356.
Eilon, S., King, J. \& Hutchinson, D. 1966. A study in equipment replacement. Operational Research Quarterly, 17(1): 59-71.

Ekeocha, R.J.O., Odukwe, A.O. \& Aguwambaa, U. J. C. 2011. Machinery replacement problems model. World Journal of Engineering and Pure and Applied Science, 1(3): 81.

Hunt, D.R. 1974. Eight Years of Cost Monitoring, Working Paper No. 74-1544, ASAE, St Joseph,MI.

Hunt, D.R. 1977. Farm Power and Machinery Management: Laboratory Manual and Workbook, 7th ed., Iowa State University Press, Ames, IA.

Hunt, D.R. Farm Power and Machinery Management, Tenth Edition, Iowa State University Press, Ames. USA. 2001.

Igbeka, J.C. 1986. “Economic evaluation of tillage operations in some mechanized farms in Nigeria", $A M A, 17(2)$ : 17-22.

Jin, D. \& Kite-Powell, H.L. 2000. Optimal fleet utilization and replacement. Transportation Research Part E36, 3-20.

Morris, J. 1998. Estimation of tractor repair and maintenance costs. Journal of Agricultural Engineering Research, 41(3): 191-200.

Offiong, A., Akpan, W.A. \& Ufot, E. 2013. Development of vehicle replacement programme for a road transport company. International Journal of Applied Science and Technology, 3(2): 31-35.

Perry, G.M., Bayaner A. \& Nixon C.J. 1990. The effect of usage and size on tractor depreciation. Am. J. Agr. Econ., 72(2): 317-325.

Ward, S. 1990. "Tractor ownership costs", AMA, 21(1): 21-3. 